\title{
Modeling and Simulation of Wind Solar Hybrid System using Matlab/Simulink
}

\author{
Obaidullah Lodin, Nitin khajuria, Satyanand Vishwakarma, Gazia Manzoor
}

\begin{abstract}
This article is a simulation, designing and modeling of a hybrid power generation system based on nonconventional (renewable) solar photovoltaic and wind turbine energy reliable sources. The primary premeditated system is the solar electric generator, consisting of six models and series connected to each other, based on predicted-P\&O and connected to a MPPT controller and DC/AC converter, system is associated with PMSG (permanent magnet synchronous generator). The main purpose of this article is to interconnect systems to generate maximum power for single auxiliary phase loading, as well as the solar PV generator and systems of wind turbines for simulation with execution use of Simulink / MATLAB. The results of this simulation indicate that the hybrid power system is planned for stability, reliability, efficiency and model. Solar PV generator and wind turbine from the use of a renewable energy source (for maximum voltage generation).The solar photovoltaic module executable in MATLAB / Simulink captures five parameters, series parameters and shunt resistance is an inverse photovoltaic saturation flow and an ideal factor.
\end{abstract}

Keywords-MPPT algorithms, irradiance, Perturb-observe, wind power etc.

\section{INTRODUCTION}

In electricity systems renewable energy sources are playing a significant and fundamental role, and utilization ofphotovoltaic solar energy is rising exceptionally day by day.Photovoltaic panels and electrical inverters are used to generate solar power. In nature, the output power generated. By the photovoltaic panels is discontinuous and varies depending on the level of irradiancy, temperature, aging ofthe panels, various orientations etc [1].

Revised Manuscript Received on July 20, 2019.

Obaidullah Lodin, Department of Electrical Engineering ,Chandigarh university,Punjab,India (E-mail: obaidullah.lodin@gmail.com)

Nitin khajuria, Department of Electrical Engineering, Chandigarh university,Punjab, India (E-mail: nitinkhajuria93@gmail.com) Satyanand Vishwakarma,Department of Electrical Engineering Chandigarh university,Punjab, India (satya0217@gmail.com)

Gazia Manzoor, Department of Electrical Engineering, Chandigarh university, Punjab, India (Email: ergaziaqadri@gmail.com)
In several implementations, particularly in rural areas, a solar photovoltaic system is more cost effective andenvironmentally friendly. This work develops and reveals the fundamental combination of the photovoltaic array aswell as examines the substantially different outputs characteristics of the solar photovoltaic array under differentconditions along with variations in temp, changes in irradiance and various internal resistances to illustrate thedifferent impacts of the parallel and the series solar PV array. The article discusses the model of a photovoltaic cellon the basis of equation of Shockley diode in MATLAB [2]. A comparison was also discussed between double andsingle diode models of the cell of solar photovoltaic's. This work has generally designed the feature model of aphotovoltaic cell with inverters and filters. The hybrid electric system integrates of two or more non conventionalenergy sources. There are certain benefits; it is more efficient than separate productivity, cost, mobility andreliability of energy sources. Moreover, it is mostly a few financial and environmental benefits, but also achievablewith up and down production costs.

\section{i. Principle operation}

When sunlight is irradiated, a photovoltaic cell generates current and the pair of electron holes is generated, while photovoltaic cell equipment absorbs photons with an energy that exceeds the material's band gap. These generate dphotons are carriers that remove this cell's internal electrical fields and help to the current when the external circuitis linked to the cell.

\section{ii. Photovoltaic cell corresponding circuits}

Two types of diodes and established equivalent circuit shown in Figure $1 \& 2$ can represent a photovoltaic cell. 


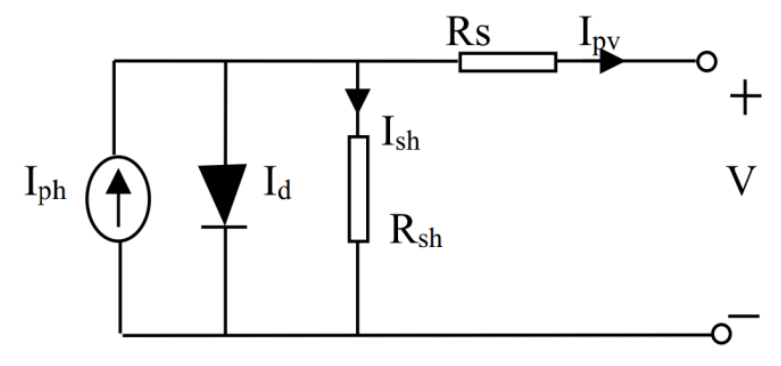

Fig1. Circuit of single diode

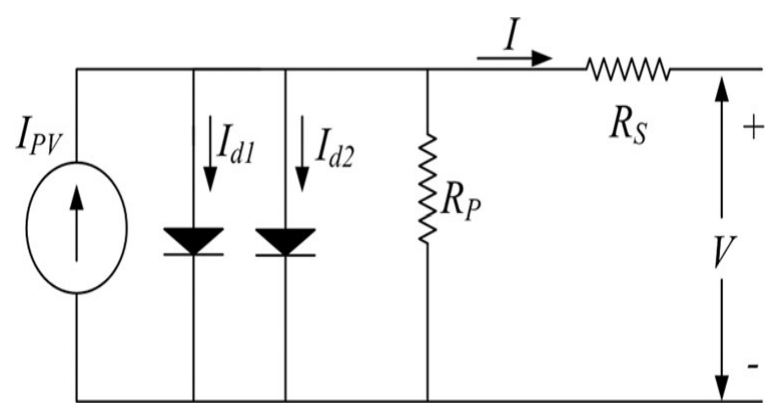

Fig2. Circuit of double diode

Whenever sun light irradiated to photovoltaic's cell, it generates direct current that varies widely sequentially withphotovoltaic radiation, and the model could be enhanced by adding shunt resistance (RP) and series (Rs) effects. Rsis initiated here to take into account internal losses and voltage drops due to current flow and Rp reflects the leakageof current to the surface whenever diodes are reversed [3-6].

\section{iii. Comparison of double and single diodes models}

Any double diode model reflects the impact of free electron and pair of photons recombination. However, it actuallyincreases the number of equations, and also unspecified parameters, attempting to make simulations slight, complex,but greater precise than the single - diode model. Mathematical errors are less in the single in view of mathematicalcalculations and the number of iterations.

\section{Photovoltaic Cell}

The photovoltaic cell is one of the semiconductor devices that absorbing and converting the photon energy thatapproaches energy from sunlight radiation. In the perfect photovoltaic cell model, it is extremely complex todetermine the parameter associated with cell temp and

Which rises the response time of the process. On the contrary, steady state oscillation around the MPP isproducedby enlargement the size of perturbation. radiation intensity such as ILG, IOS, Rsh, and Rs.Manufacturers of photovoltaic's arrays give various observational conceptual parameters including current of shortcircuit ISC, voltage of open circuit VOC, max voltage point $\mathrm{Vm}$, max power point current Im, and max powerpoint Pm.

$I=I_{P V}-I_{d 1}-I_{d 2}-\frac{V+I R_{s}}{R_{p}}$

Whereas $R_{p}$ and $R_{s}$ are the parallel and series resistance, correspondingly. Althoughthe diodes thermal voltage is $\mathrm{V}_{\mathrm{T}}$. The created current by lights is $\left(\mathrm{I}_{\mathrm{PV}}\right)$

$$
I_{P V}=\left(I_{P V-S T C}+K_{I}\left(\mathrm{~T}-T_{S T C}\right)\right) \frac{G}{G_{S T C}}
$$

$\mathrm{I}_{\mathrm{P} \text { V_STC }}$ is computed in the standard test condition (STC), i.e., irradiance $\mathrm{G}=1000 \mathrm{~W} / \mathrm{m}^{2}$ and temperature $\mathrm{T}=298 \mathrm{~K}$ $\left(25^{\circ} \mathrm{C}\right)$. Variable $K_{I}$ is frequently delivered by the constructor, which iscoefficientof the $\mathrm{I}_{\mathrm{SC}}$. Diode'ssaturation current is specified by [7]

$I_{d 1}=I_{d 2}=\frac{I_{S C-S T C}+K_{1}\left(\mathrm{~T}-\mathrm{T}_{\mathrm{STC}}\right)}{\exp \left(\left(V_{O C-S T C}+K_{V}\left(T-T_{S T C}\right)\right) / V_{T}\right)-1}(3)$

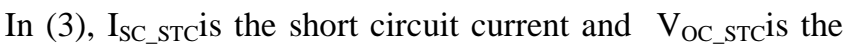
open circuit voltage in standard test condition (STC). The voltage's temperature factor is denoted by Variable $K_{V}$.

\section{PERTURB AND OBSERVE (P\&O) METHOD}

On account of simplicity of execution as presented in diagram below, the Conventional Perturb \& Observe algorithm isapplied widely. Until the operative point unites at the MPP, it is a constantprogression of observation and perturbation. The $\mathrm{P} \& \mathrm{O}$ algorithmequates the voltage and power of time (K) along with the model at a time (K-1) and guesses the time to method to maximum power point. If the power modification is $+v e$, then the power transformation of the solar panel is done by aminor voltage perturbation; voltage perturbation is constant in the equivalentpathway. On the other handnegative delta power, point out that the maximum power point is far-off and the perturbation is reduced to trace the maximum power point. The abstractof the conventional $\mathrm{P} \& \mathrm{O}$ is figured out in Table 1 . Hence, like this the entire P-V curve is checkered by minor perturbations to discover the maximum power point

Variations in the $\mathrm{P} \& \mathrm{O}$ algorithm have been proposed by numerousscholars to overwhelm thesteady state oscillationsand response time issue. 


\section{PREDICTIVE_PO BASED MPP TRACKER}

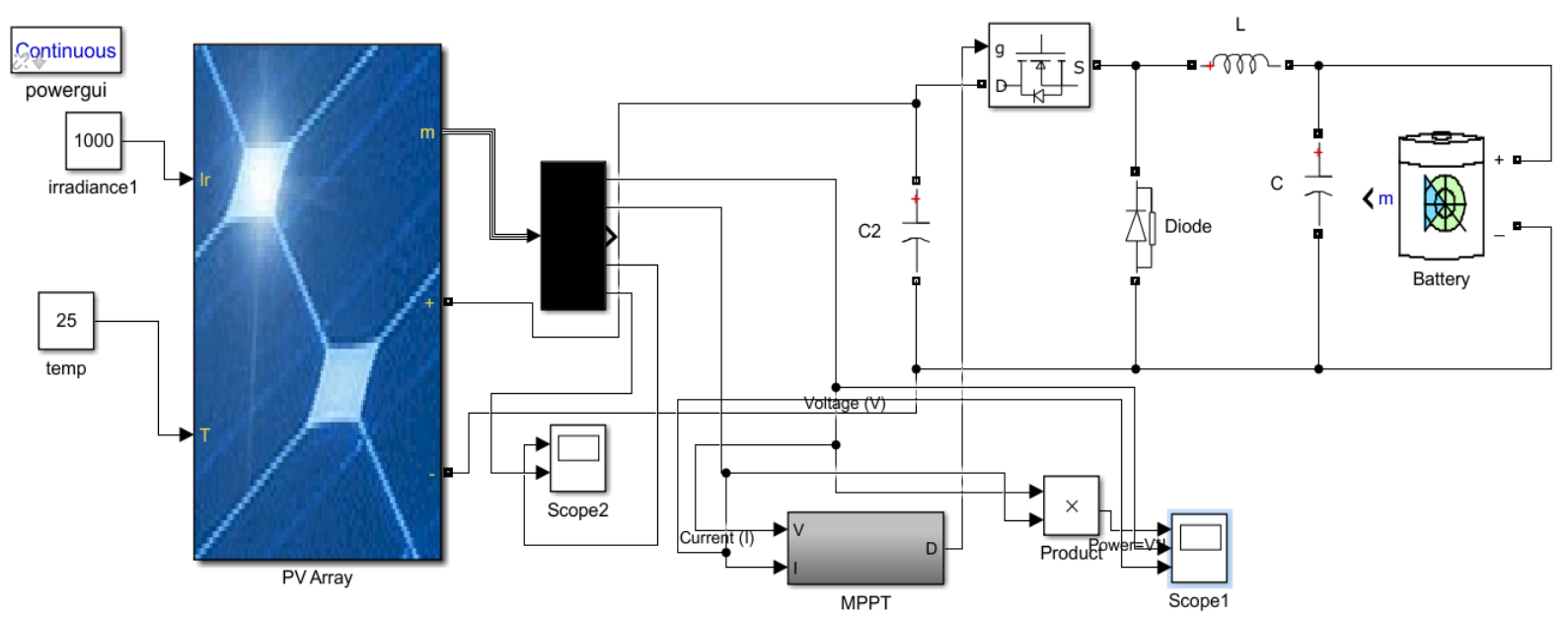

Fig3. Solar PV model simulation in Simulink

If a filter regulates its conveyancetask by itself stated by an optimizationprocess is called an adaptive filter (AF). On account of complexness of the optimization algorithms, digital filters are also adaptive filterswhichexecute digital signal processing (DSP)\&adjust their actbuilt on the incoming signals to the filter. By means ofcompare, a nonadaptive filter has static filter factors (thatjointlycustom the transfer functions).

A. An Adaptive FIR Filter executionby usingthe least mean squares (LMS) Algorithm

LMS procedures are a session of adaptive filter applied to simulate a preferred filter by defining the filter factors that narrate to creating the LMS of the error signal.

\section{B. Least Mean Square (LMS) Algorithm}

For numerous age, the adaptive filter is a widespread and operativedevice for examining signals. Let the length of the adaptive filter for instance $L$. For input vector $x(n)$, the arrangementproduces output signal $y(n)$ as presented in the subsequent equation,

$$
y(n)=x(n) \mathrm{T} w(n)=w(n) T x(n)
$$

The weight updated vector for the LMS algorithm is specified by the subsequent equation;

$$
w(n+1)=w(n)+\mu x(n) e(n)
$$

Where $\mu$ is the step size, the whole PV system which has been workingis shown in figure4 where MPPT block uses PREDICTIVE-PO based tracking method.

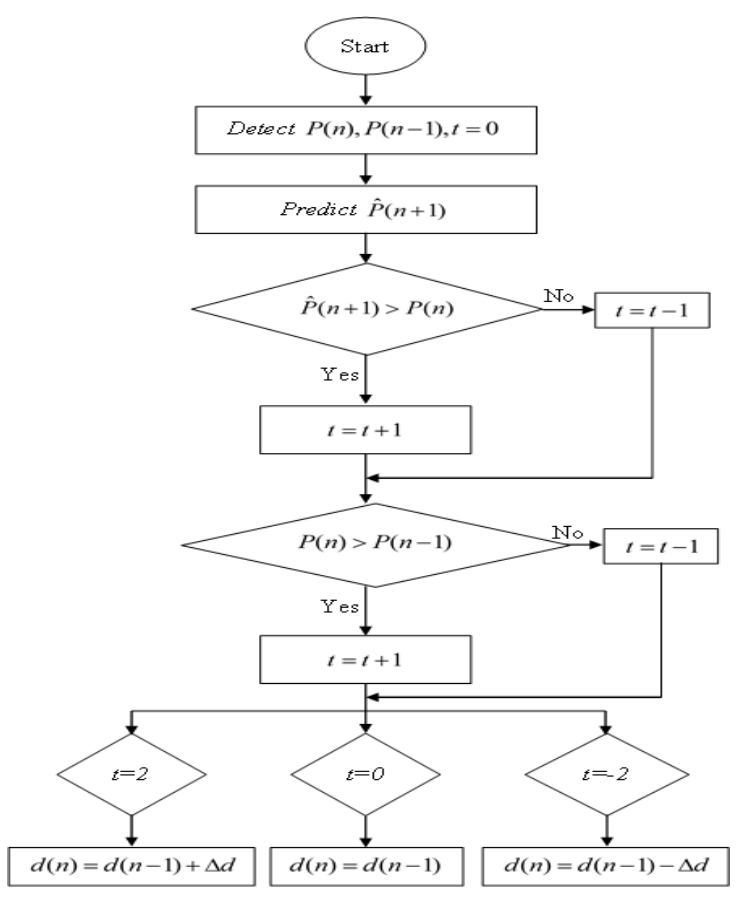

Fig.4: Flowchart of MPPT algorithm based on LMS based predictive power

Whole Photovoltaic system designed for efficient mppt tracking has been shown in figure 2.Due to the variance in irradiance and temperature, the voltages and currents cannot fed directly to the energy storage units or appliances, these need to be first fed to the controller device which tracks the maximum power for the available voltage and current in such a way that an energy storage unit which consists of inductance and capacitance circuit hold the extra powerfor some time when there is extra power generation from previous cycle and donates the power when there is less Power production in previous round.This on-off time set is provided by a mosfet/IGBT switch to the LC circuit using the MPPT control unit.

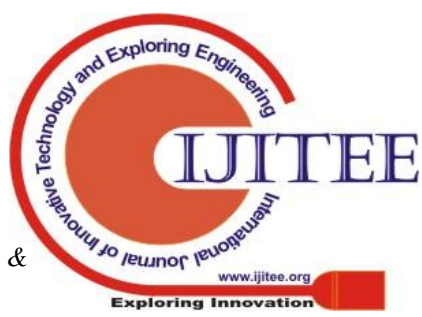




\section{Modeling and Simulation of Wind Solar Hybrid System Using Matlab/Simulink}

The LC circuit and switch constitutes the buck booster system which works on DC-DC conversion level. In existed algorithm of perturb-observe; only current and previous readings were utilized without any consideration of optimized future power values. In proposed methodology, predictive power is induced which is optimized using least mean square algorithm in order to maintain optimum maximum point of power. In flowchart below, $\mathrm{p}(\mathrm{n}+1)$ is predictive power[8].

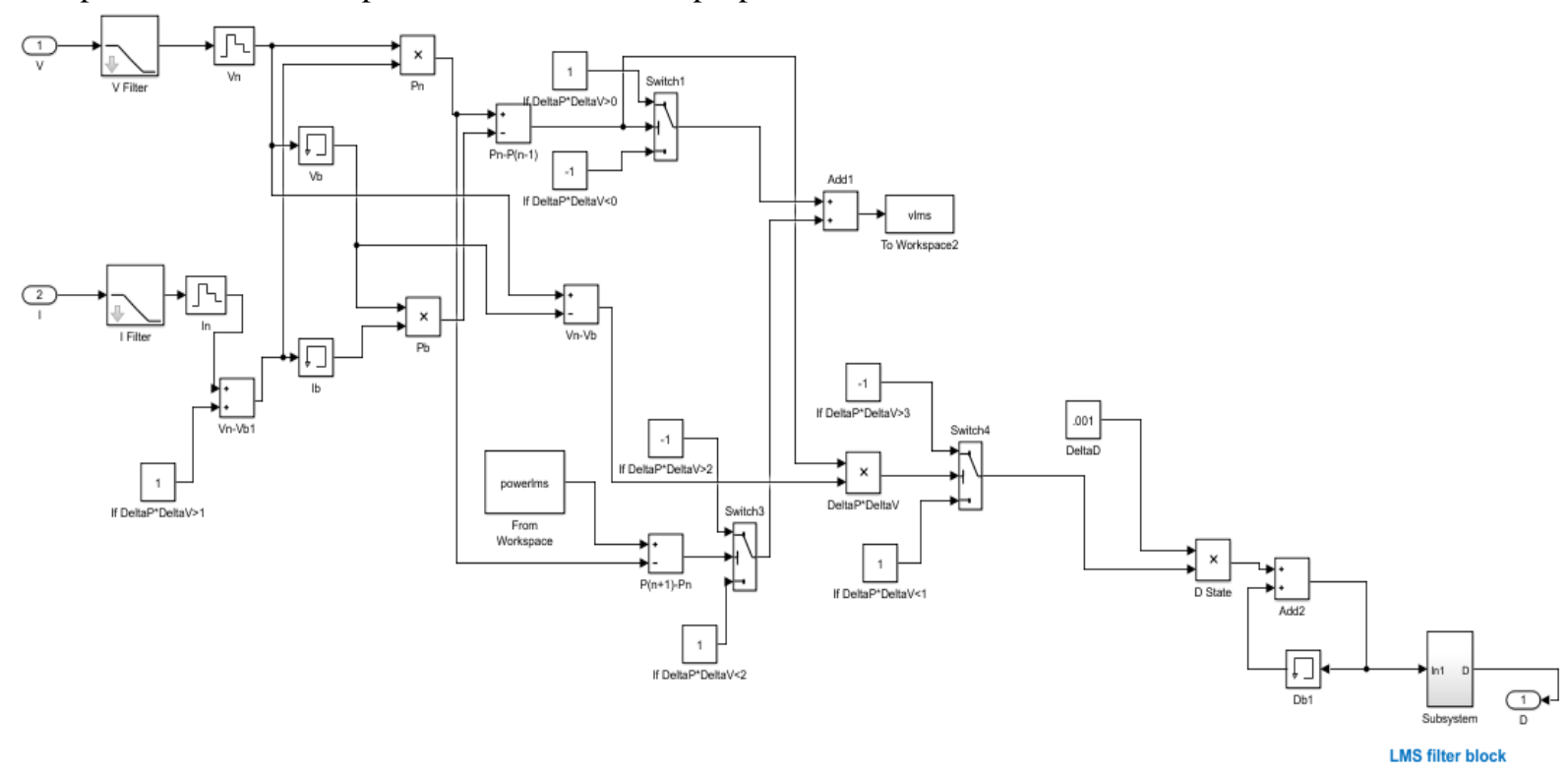

Fig.5: Flowchart implementation of MPPT algorithm based on LMS based predictive power

\section{Result of SPV simulations}

Simulation results are carried out for an array consists of 40 series modules and 10 parallel modules. User defined attributes of module used are as follows. Open circuit voltage $(\operatorname{Voc}(\mathrm{V}))$ is $42, \operatorname{Isc}(\mathrm{A})=29.7$, Voltage at MPP $\mathrm{Vmp}(\mathrm{v})=36$, ,current at $\mathrm{MPP} \operatorname{Imp}(\mathrm{A})=27.7$, cells per module $=10 \mathrm{Fig}$. 6 shows the IV-PV plots of array when it works at optimum conditions. Fig. 7 Shows the PV power waveforms using traditional PO method and PREDICTIVEPO based improved method. The performances of proposed MPPT algorithm have been evaluated at $1000 \mathrm{~W} / \mathrm{m}^{2}$ and $25^{\circ}$ temperature. Table two gives the power values using two compared methods [9].
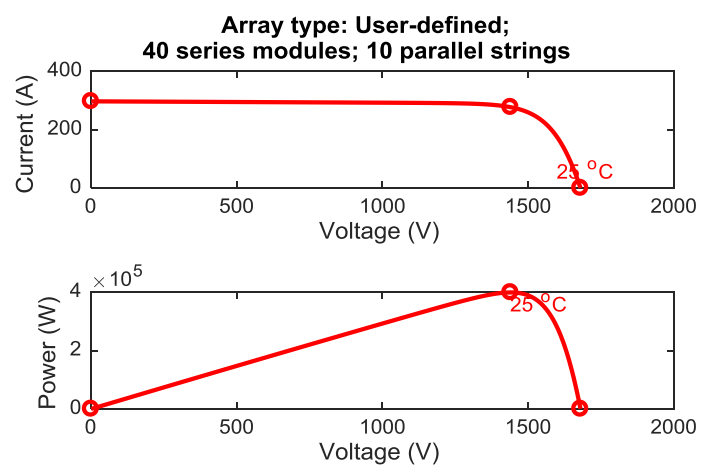

Fig. 6: IV-PV plots of array in optimum conditions

It has been found that proposed method achieves highest point far early than traditional PO method. In this work, buck-booster DC-DC converter is used and mosfet switch is used to on-off the energy storage circuit.

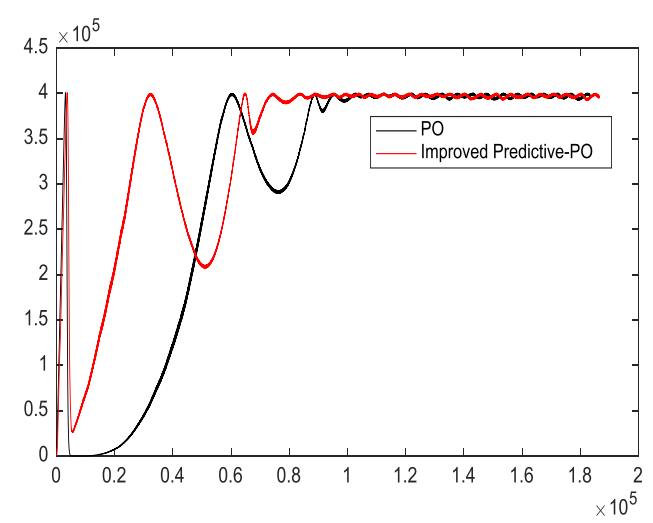

Fig.7: Comparison of power output using perturb-Observe and Proposed PREDICTIVE-PO based MPPT tracking

It is also been found that proposed method gives power with least fluctuation variance and achieves stability in peak value earlier than $\mathrm{PO}$ method.

\section{Wind Turbine Modeling}

Energy of wind is a source that is friendly to the environment and unending. Moreover, one of the exciting sourcesof renewable energy for future demand may be a wind energy generation system. Its converting wind kinetic energyinto mechanical energy, and the magnitude of this mechanical energy that has been converted depends on the windspeed and air 
density [10]- [14]. Wind turbines power (Pm) is determined by this equation:

$\mathrm{Pm}=1 / 2 \mathrm{Cp}(\lambda, \beta) \rho \mathrm{Aw} 3(9)$

Where:

$\mathrm{W}=$ Wind $\mathrm{speed}(\mathrm{m} / \mathrm{sec})$

$\rho=$ Density of Air $(\mathrm{Kg} / \mathrm{m} 3)$

$\mathrm{A}=$ Turbine blades area $(\mathrm{m} 3)$

$\mathrm{Cp}=$ Turbine performance coefficient

$\beta=$ Angle of blade pitch (degree)

$\lambda=$ Rotor blade tip velocity ratio to wind velocity

The Cp coefficient is the fraction of kinetic energy that is converted into mechanical energy through wind turbine,and it's depending on the ratio of tip velocity $(\lambda)$.For calculation of wind turbine torque (Tm) uses this equation:
$\mathrm{Tm}=1 / 2 \rho \mathrm{ACp}(\mathrm{w} / \lambda)(10)$

Wind turbine optimal power curve is determining different operation regions and different speed of wind as ratedwind speed, cut in wind speed, cut out wind speed [15].

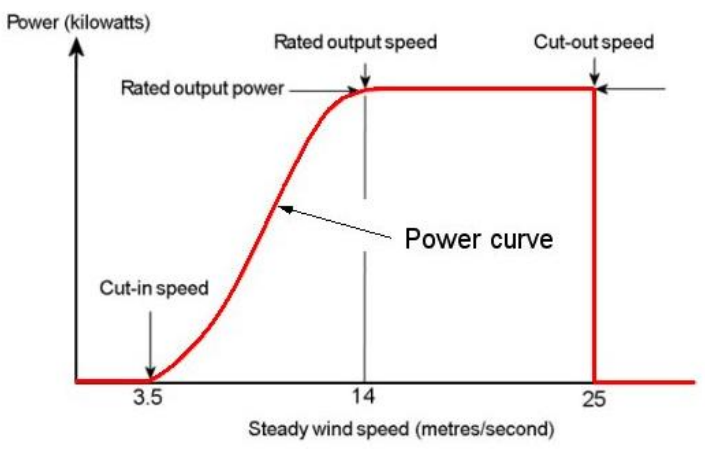

Fig.8: Typical wind turbine power output with steady wind speed

Joint the turbine of wind system and PMSG Generator uses software Simulink /MATLAB and seen in Fig9.

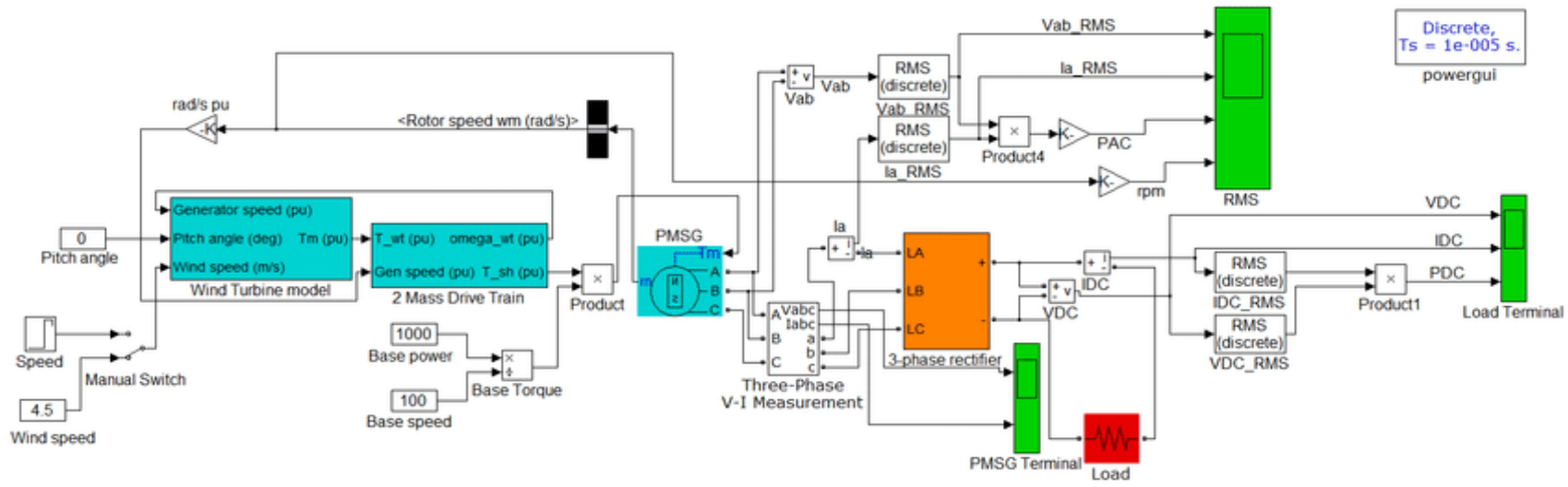

Fig9. Wind turbine model simulation in Simulink.

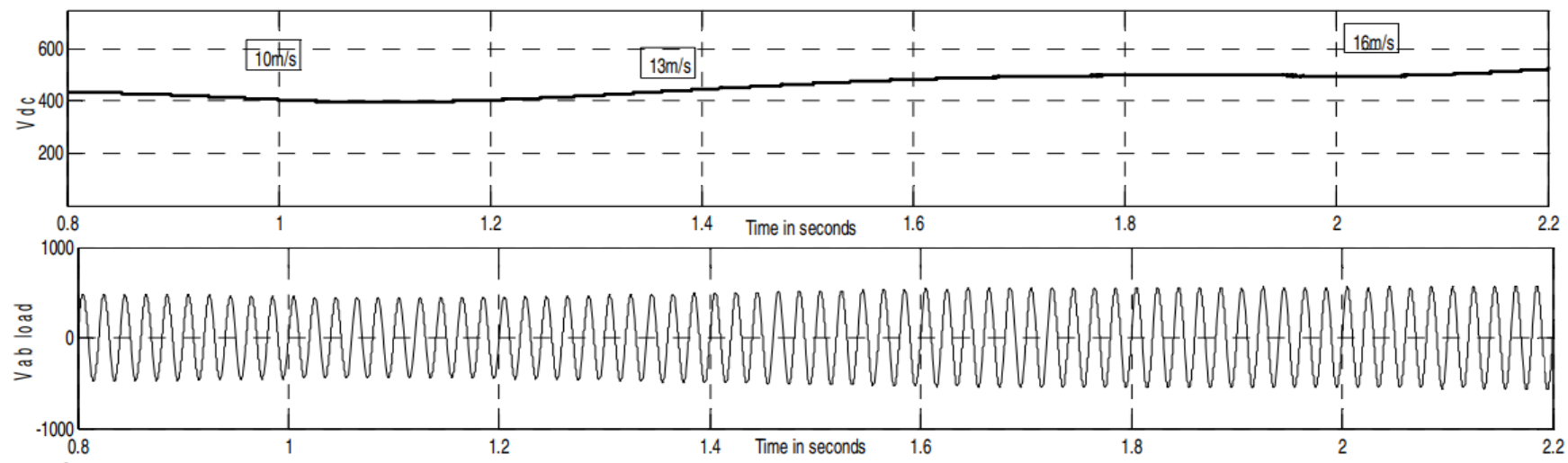

Figure10. Dcand AC voltage PMSG under different wind speed
The PMSG turbine for wind power generation has been simulated accurately and the DC and AC output have shown in form of voltage waveforms.

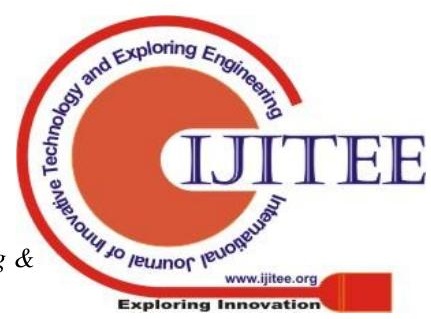


VII. Grid Connected Hybrid power system simulation and modeling photovoltaic and wind turbine system and providing single phase AC load.

Perhaps the hybrid power system, which consists of two non conventional energy sources, the combination of solar

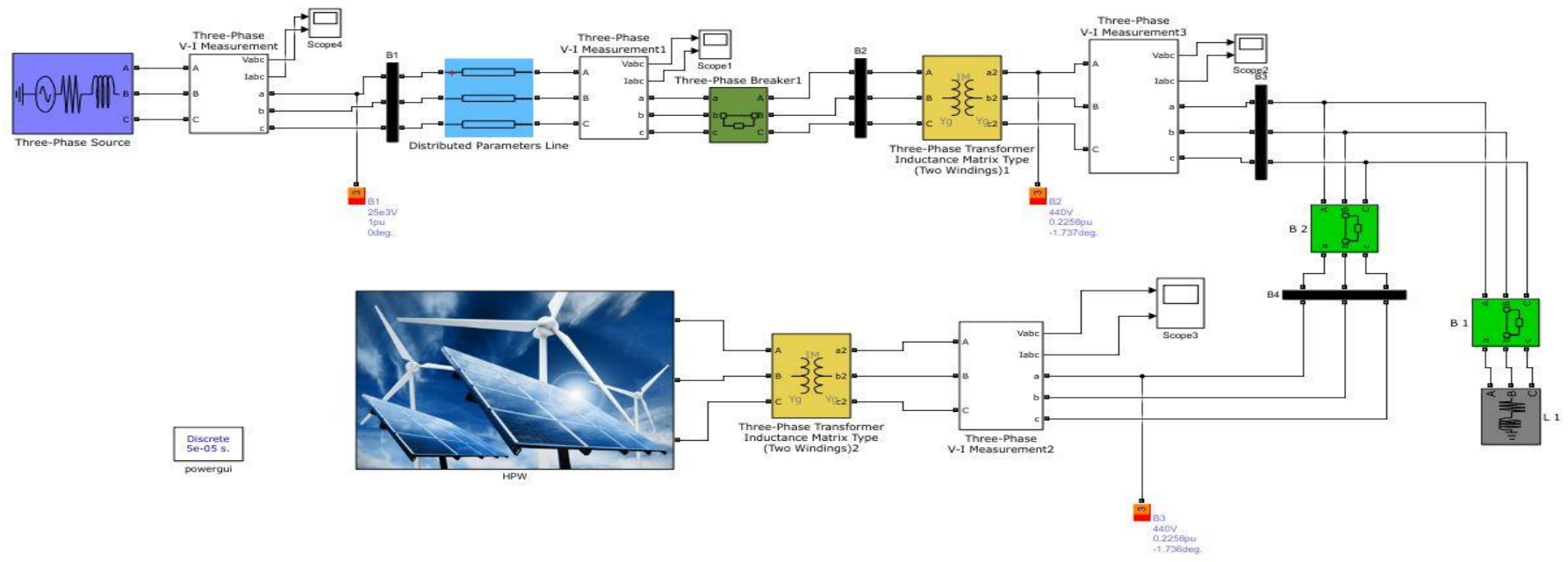

Fig11. Wind and Solar photovoltaic hybrid power system connection with Grid system model Simulink.

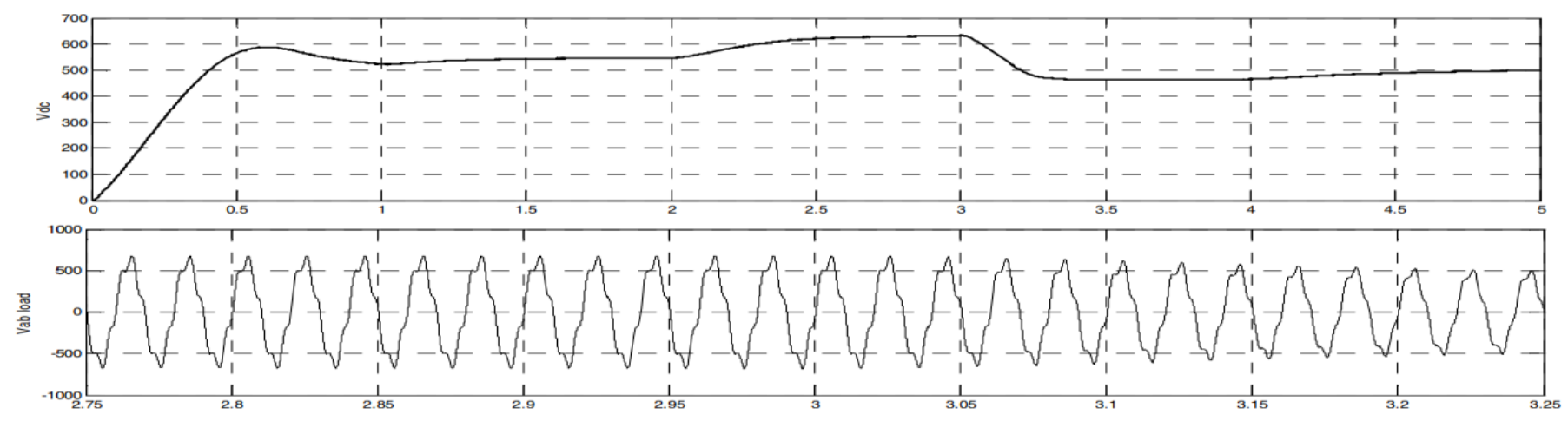

Fig12: Output for both wind speed and solar

The above figure represents the voltage waveform of wind turbine and solar photovoltaic system based on the predictive -P\&O MPPT technique.

\section{CONCLUSION}

The objective of this article is the integration of wind turbine system with solar photovoltaic's system to demonstratethe efficiency, reliability, and maximum power generation of a hybrid power system. Then each system was premeditated and modeled unaccompanied and subsequently joined to compare the voltageand power variation use of Simulink / MATLAB. In fact, the effects of the simulation actually demonstrate theefficiency of the planned hybrid power system, in order to generate maximum power for moist summer weatherin various countries trying to use renewable energy. Recently, the power generation of average lightness and windvelocity are valuable and beneficial. The solar cell's performance depends mainly on climate conditions. Entirefield tests to monitor solar cell performance are highly costly. A comprehensive simulation study can accumulateresources and time, however. All these concerns are covered by the solar photovoltaic's model implemented usingMATLAB /Simulink. The Simulink execution of the solar photovoltaic model has five parameters in the description.

\section{REFERENCES}

[1] B H Khan, "Non-Conventional Energy Resources," Tata McGrawHill Pub.Co., 2009.

[2] Gazia Manzoor, Kamalkant Sharma, Satyanand Vishwakarma"PSOGSA based MPPT Algortihm for Photovoltaic Sytems", International Journal of Recent Technology and Engineering (IJRTE), ISSN:22773878, vol.7, issue-6S4, April 2019

[3] H.Renaudineau,F.Donatantonio,G.Petrone, G.Spagnuolo, J. P. Martin, S.Pierfederici, J. Fontchastagner,"A PSO-based global MPPT technique for distributed PV power generation," IEEE Trans. Ind. Electron., vol. 62, no. 2, pp. 1047-1058, Feb. 2015

[4] Vpiasha Sharma, Harpreet Kaur, Inderpreet Kaur,'Design and Implemetation of Multi Junction PV cell for MPPT to improve the Transformation efficiency "International Journal of Recent Technology and Engineering (IJRTE), ISSN:2277-3878, vol.7, issue-6S4, April 2019 
[5] K. Sundareswaran, V. Vigneshkumar, P. Sankar, S. P. Simon, P. S. R. Nayak, and S. Palani, "Development of an improved P\&O algorithm assisted through a colony of foraging ants for MPPT in PV system," IEEE Trans. Ind. Informat., vol. 12, no. 1, pp. 187-200, Feb. 2016.

[6] D. Teshome, C. H. Lee, Y. W. Lin, and K. L. Lian, "A modified firefly algorithm for photovoltaic maximum power point tracking control under partial shading," IEEE J. Emerg. Sel. Topics Power Electron., vol. 5, no. 2, pp. 661-671, Jun. 2017.

[7] X. Liu, P. Wang and P. C. Loh, "A Hybrid AC/DC Microgrid and Its Coordination Control," IEEE Transaction on smart grid, vol. 2, June 2011, pp. 278 - 286.

[8] J. Ahmed and Z. Salam, "A critical evaluation on maximum power point tracking methods for partial shading in PV systems," Renewable Sustain. Energy Rev., vol. 47, pp. 933-953, Jul. 2015.

[9] Obaidullah Lodin, Inderpreet Kaur, Harpreet Kaur "Predictive- P\&O Mppt Algorithm for Fast and Reliable Tracking of Maximum Power Point in Solar Energy Systems", International Journal of Recent Technology and Engineering (IJRTE), ISSN:2277-3878, Volume-7, Issue-6S4, April 2019

[10] A. M. Osman Haruni, Michael Negnevitsky, Md. Enamul Haque, A.Gargoom, "A Novel Operation and Control Strategy for a Standalone Hybrid Renewable Power System," IEEE Transactions on sustainable energy, vol. 4, no. 2, April 2013,pp.402-413.

[11] F. Paz and M. Ordonez, "Zero oscillation and irradiance slope tracking for photovoltaic MPPT,” IEEE Trans. Ind. Electron., vol. 61, no. 11, pp. 6138-6147, Nov. 2014.

[12] Shefali, Harvinder Singh, Sachin Kumar, Inderpreet Kaur," Designing and Imulation of Solar module in the Islanded network of a solar PV microgrid", International Journal of Recent Technology and Engineering (IJRTE), ISSN:2277-3878, Volume-7, Issue-6S4, April 2019

[13] S. K. Kollimalla and M. K. Mishra, "Variable perturbation size adaptive P\&O MPPT algorithm for sudden changes in irradiance," IEEE Trans. Sustain. Energy, vol. 5, no. 3, pp. 718-728, Jul. 2014.

[14] F. Ding, P. Li, B. Huang, F. Gao, C. Ding, W. Chengshan, "Modeling and Simulation of Grid-connected Hybrid Photovoltaic/Battery Distributed Generation System," 2010 China International Conference on Electricity Distribution, Sept 2010, pp. $1-10$

[15] B. Widrow and S.D. Stearns, Adaptive Signal Processing, Prentice Hall, 1985.

\section{AUTHORS PROFILE}

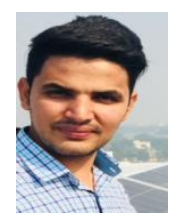

Obaidullah Lodin,received the B.E. degree in Electrical and Electronics Engineering from Visvesvaray Technological University, Bangalore, Karnataka, India in 2017, He is currently pursuing Master In Electrical Engineering From Chandigarh University, Punjab, India His research interests include photovoltaic modeling and control, energy conversion from renewable sources, Power System, Machine Control and power electronics.

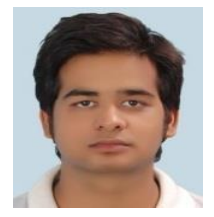

Nitin Khajuria,received the B.E. degreein Electronics and Communication Engineering from Punjab University,Chandigarh, India in 2016, He is currently pursuing Master In Electrical Engineering From Chandigarh University, Punjab, India. His research interests include power electronics, signal and processing, circuit designing and Power system.

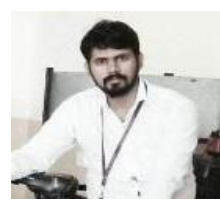

Satya Vishwakarma, He is working as Assistant professor in Electrical Engineering department in Chandigarh University, Punjab. He did his M.TECH in Power Systems Engineering in Galgotias University Noida. He is having wide area of interest in the field of Electric vehicles and Renewable generation.

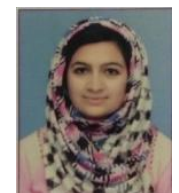

Gazia Manzoor,received the B.Tech. degreein electrical and Renewable Energy Engineering from Baba Ghulam Shah badshah University (BGSBU), Rajouri, Jammu \&Kashmir, India in 2017, She is currently pursuing Master In Electrical Engineering From Chandigarh University, Punjab, India. Her research interests include Renewable Energy, energy conversion fromrenewable sources, power system. 